\title{
Can the CEIBA Cocktail Designed for Human Cytochrome P450 Enzymes be Used in the Rat for Drug Interaction Studies?
}

\author{
Paulo Magalhães ${ }^{\mathrm{a}, \mathrm{b}, \mathrm{c}, \mathrm{d}}$, Fernando de Andrés $^{\mathrm{d}, \mathrm{e}}$, Amílcar Falcão $^{\mathrm{a}, \mathrm{b}}$, Adrián LLerena ${ }^{\mathrm{d}}$, Gilberto Alves ${ }^{\mathrm{b}, \mathrm{c}}$ \\ ${ }^{a}$ Laboratory of Pharmacology, Faculty of Pharmacy, University of Coimbra, Pólo das Ciências da Saúde, Azinhaga de \\ Santa Comba, Coimbra, Portugal. ${ }^{\mathrm{b}}$ Center for Neuroscience and Cell Biology, University of Coimbra, Coimbra, Portugal. \\ ${ }^{\mathrm{c}}$ Health Sciences Research Centre, University of Beira Interior, Rua Marquês d'Ávila e Bolama, Covilhã, Portugal. ${ }^{\mathrm{d}}$ \\ Clinical Research Centre, Extremadura University Hospital and Medical School, Badajoz, Spain. \\ ${ }^{\mathrm{e}}$ Department of Analytical Chemistry and Food Technology, Faculty of Pharmacy, University of Castilla-La Mancha, \\ Albacete, Spain.
}

Received, November 16, 2016; Accepted, December 15, 2016; Published, Dec 16 ${ }^{\text {th }}, 2016$.

\begin{abstract}
Purpose - The CEIBA cocktail consisting of caffeine (CAF), omeprazole (OZ), dextromethorphan (DM) and losartan (LOS) was previously proposed for the clinical phenotyping of five major human cytochrome P450 (CYP) isoenzymes. This work aimed to assess the usefulness of CEIBA cocktail to study non-clinical drug interactions in the rat. Methods - Wistar rats were divided into five groups to receive a single-oral dose of each probe drug (CAF, OZ, LOS, DM), individually or in combination as a cocktail. Plasma concentrations of the probe drugs and their metabolites [paraxanthine (1,7-X), 5hydroxyomeprazole (5-OZ), losartan carboxylic acid (E-3174), dextrorphan (DX) and 3-methoxymorphinan (3-MM)] were determined by LC-MS/MS, and the corresponding pharmacokinetic parameters were estimated by non-compartmental analysis. The $\mathrm{AUC}_{0-\mathrm{t}}$ and $\mathrm{C}_{\max }$ drug/metabolite ratios (phenotypic metrics) were calculated for each probe drug and compared (probe alone versus cocktail). Results - The primary analysis of the pharmacokinetic data suggested the occurrence of pharmacokinetic-based drug interactions when the probe drugs were concurrently administered; such interactions were documented for CAF, 1,7-X, DX and E-3174. Nevertheless, except for the LOS/E-3174 probe drug-metabolite pair $(p<0.05)$, there was little evidence that the probe drugs interacted metabolically as the metabolic ratios calculated were similar in both approaches. Moreover, no evidence was found for relevant pharmacodynamic interactions. Conclusion - CEIBA cocktail seems to be a useful tool to investigate drug interactions involving CYP isoenzymes in the rat, particularly at the level of CYP1A2, CYP2D1/2 and CYP2D2 isoforms using the CAF/1,7-X, OZ/5-OZ and DM/DX metabolic ratios, respectively.
\end{abstract}

This article is open to POST-PUBLICATION REVIEW. Registered readers (see "For Readers") may comment by clicking on ABSTRACT on the issue's contents page.

\section{INTRODUCTION}

Nowadays it is consensual that a great part of interindividual variability in drug response is related to differences in the capacity of drugmetabolizing enzymes, especially the cytochrome P450 (CYP) isoenzymes (1-4). Although the differences in drug metabolism capacity is greatly determined by genetic polymorphisms, additional intrinsic and extrinsic factors are able to modulate CYPs activity, contributing thus to the actual drug metabolic phenotype (3-5).

As acknowledged by Vital-Lopez et al. (6), there is a gap between gene expression and metabolic phenotype, and the kinetic data may be useful to understand how these processes are connected. Indeed, CYPs genotype cannot accurately predict the actual metabolic phenotype for all individuals (7-9). Therefore, a biomarker of the functional metabolic state (phenotype) is more valuable than a mere genetic biomarker. Actually, genotyping tests are often limited to distinguish drug response phenotypes because poor CYP genotype/metabolic phenotype correlations can also occur as a result of drug-drug interactions $(1,5)$. Accordingly, extensive efforts have been directed towards development of phenotyping assays to evaluate the actual drug metabolizing activity of CYP isoenzymes. Such assays involve the administration of substrates (probes) which are selectively metabolized by a given CYP isoenzyme, and the substrate/ metabolite concentration ratio, or the metabolic

Corresponding author: Gilberto Alves, PharmD, Ph.D; Faculty of Health Sciences, University of Beira Interior; CICS-UBI - Health Sciences Research Centre, University of Beira Interior Av. Infante D. Henrique; 6200-506 Covilhã, Portugal; E-mail address: gilberto@fcsaude.ubi.pt 
ratio, is calculated. Numerous cocktails are reported to phenotype humans (4,10-24), e.g., Cooperstown 5+1 (18), Karolinska (19), SanofiAventis (20), Inje (21), CIME (22), Basel (23), Geneva (24), and CEIBA cocktail $(4,25)$.

The availability of an appropriate cocktail approach to simultaneously assess the activity of different CYP isoenzymes is advantageous not only in clinical setting but also in non-clinical arena, particularly to investigate drug interactions (2,26-30). Nevertheless, CYP-specific probe drug cocktails have been designed to man $(2,4,10$ $24,26)$, and very few studies have tested their use in animal models $(2,26,31)$. Moreover, a current matter of concern is the emergence in literature of several works conducted in the rat by direct application of probe drug cocktails specifically developed for phenotyping human CYP isoenzymes (32-38). However, humans differ from animals in isoform composition, expression and catalytic activities of drug-metabolising CYP isoenzymes (39), and specific works are required to avoid biased results and/or an erroneous interpretation of the metabolic data obtained.

Consequently, as the rat is certainly the animal model most frequently used $(2,26)$, it is imperative to investigate the extrapolation of a phenotyping cocktail approach designed for human to rat before its widespread use, especially considering the pharmacokinetics behaviour of the probe drugs combined and the potential occurrence of drugdrug interactions $(26,31,40)$. Such idea was already explored for three human cocktails $(2,26,31)$ and it is fully justified for any other cocktail intended to be used in rat species, which constitutes the rational basis for performing the present study.

Recently, we proposed the CEIBA cocktail consisting of four probe drugs [caffeine (CAF), omeprazole (OZ), dextromethorphan (DM) and losartan (LOS)] for the simultaneous phenotyping of the five major human drug-metabolizing CYP isoenzymes (CYP1A2, CYP2C9, CYP2C19, CYP2D6 and CYP3A4) in just one assay $(3,4,25)$. Nonetheless, its potential application in the rat has never been studied. Therefore, bearing in mind the aforementioned issues, this work was aimed to evaluate the possibility of applying the CEIBA cocktail approach to study drug interactions in the rat.

\section{MATERIALS AND METHODS}

\section{Chemicals and materials}

DM hydrobromide, dextrorphan (DX) tartrate, 3methoxymorphinan (3-MM) hydrochloride, OZ, CAF, 1,7-dimethylxanthine (paraxanthine; 1,7-X), the internal standard (IS) levallorphan, and $\beta$ - glucuronidase were purchased from SigmaAldrich (MO, USA). LOS, losartan carboxylic acid (E-3174) and 5-hydroxyomeprazole (5-OZ) sodium salt were obtained from Santa Cruz Biotechnology (CA, USA). LC-MS-grade methanol, acetonitrile and formic acid, and analytical-grade sodium acetate, acetic acid used to prepare the $\beta$-glucuronidase treatment buffer, ammonium formate, and SOLA ${ }^{\circledR}$ cartridges for solid phase extraction (SPE) were purchased from Fisher Scientific (Geel, Belgium). Analyticalgrade potassium dihydrogen phosphate and sodium hydroxide were used to prepare the SPE buffer and were purchased from Merck (Darmstadt, Germany). Deionized water was purified through a water purification system from Millipore (MA, USA). Other compounds used were: carboxymethyl cellulose sodium salt (SigmaAldrich, MO, USA), sodium chloride $0.9 \%$ solution for injection (Labesfal, Portugal), heparin sodium 5000 I.U./mL for injection (B. Braun Medical, Portugal), and pentobarbital (Eutasil ${ }^{\circledR}$ $200 \mathrm{mg} / \mathrm{mL}$, Ceva Saúde Animal) used as anaesthetic drug. Introcan ${ }^{\circledR}$ Certo IV in dwelling cannula (22G; $0.9 \times 2.5 \mathrm{~mm}$ ) made of polyurethane from B. Braun Melsungen AG (Melsungen, Germany) and heparin-lithium tubes were also used.

\section{Animals}

Adult male Wistar rats weighting approximately 240-340 g were obtained from local certified animal facilities. The rats were kept in an environmentally controlled room (temperature $20 \pm 2^{\circ} \mathrm{C}$; relative humidity $55 \pm 5 \%$; 12 -h light/dark cycle) with free access to tap water and standard rodent diet (4RF21, Mucedola, Italy).

To perform a sequential blood sampling over time, a lateral tail vein of each rat was cannulated by an Introcan ${ }^{\circledR}$ Certo IV indwelling cannula (22G; $0.9 \times 2.5 \mathrm{~mm}$ ) under anaesthesia with pentobarbital $(60 \mathrm{mg} / \mathrm{kg}$, i.p. injection) at night on the day before the administration of the probe drugs. The rats were fasted overnight and $4 \mathrm{~h}$ post-dose administration with free access to water. Oral administrations were performed by gavage. All the animal experiments were carried out in accordance with the EU Directive 2010/63/EU for animal experiments.

\section{Experimental design}

Rats $(n=25)$ were randomly divided into five groups. The animals of each group $(n=5)$ were orally treated with a single-dose of the four probe drugs (CAF, OZ, LOS and DM) administered separately (groups 1-4) and in combination as a cocktail (group 5). The probe drugs were 
appropriately suspended in a $0.5 \%$ carboxymethyl cellulose aqueous solution and administered to rats by gavage. The group 1 was treated with CAF (10 $\mathrm{mg} / \mathrm{kg}$ ), the group 2 with OZ (20 $\mathrm{mg} / \mathrm{kg})$, the group 3 with LOS $(10 \mathrm{mg} / \mathrm{kg})$, and the group 4 received $\mathrm{DM}(20 \mathrm{mg} / \mathrm{kg})$. Lastly, all the four-probe drugs were given simultaneously to the group 5, at the same doses as when individually used. For each rat, multiple serial blood samples (approximately $0.3 \mathrm{~mL}$ ) were collected through the cannula inserted in the tail vein into heparinized tubes before dosing, and at $0.25,0.5,1,2,4,6,12$ and 24 $\mathrm{h}$ after drug administration. Plasma was subsequently obtained by centrifugation at $4^{\circ} \mathrm{C}$ and $4000 \mathrm{rpm}$ for $10 \mathrm{~min}$ and then stored at $-80^{\circ} \mathrm{C}$ until analysis of the probe drug(s) and the corresponding metabolite(s).

\section{Drug analysis}

Plasma concentration of the probe drugs and their metabolites were determined by liquid chromatography coupled to tandem mass spectrometry (LC-MS/MS) based on a previously developed methodology (4). Briefly, $100 \mu \mathrm{L}$ of plasma spiked with levallorphan (IS, $10 \mathrm{ng}$ ) were mixed with $400 \mu \mathrm{L}$ of potassium dihydrogenphosphate $0.1 \mathrm{M}$ at $\mathrm{pH} 7.5$ (extraction buffer).For the solid phase extraction step, the SPE SOLA $^{\circledR}$ cartridge was previously conditioned with $500 \mu \mathrm{L}$ of methanol and $500 \mu \mathrm{L}$ of extraction buffer and then the sample mixture obtained after the incubation process was loaded. Afterwards, the extraction cartridge was washed with $500 \mu \mathrm{L}$ of extraction buffer and then the analytes were eluted with $500 \mu \mathrm{L}$ of methanol. The eluate was evaporated at $40^{\circ} \mathrm{C}$ under a nitrogen stream and the dried residue was reconstituted in $100 \mu \mathrm{L}$ of the mobile phase. Aliquots of $10 \mu \mathrm{L}$ of the reconstituted extract were injected in the LCMS/MS chromatographic system. The LC-MS/MS chromatographic analysis of the probe drugs and their corresponding metabolites (CAF and 1,7-X, $\mathrm{OZ}$ and 5-OZ, LOS and E-3174, DM, DX and 3MM) was performed on an Agilent 1200 HPLC system (Agilent, CA, USA) using a Poroshell SBC18 column $(75 \mathrm{~mm} \times 3 \mathrm{~mm}$ internal diameter; 2.7 $\mu \mathrm{m})$ at $30{ }^{\circ} \mathrm{C}$ and a mobile phase composed by $0.1 \%$ formic acid in water and $0.1 \%$ formic acid in acetonitrile. The flow rate was $0.4 \mathrm{~mL} / \mathrm{min}$ and the elution was carried out by means of a linear gradient, with acetonitrile content increasing from $17 \%$ to $50 \%$ between 0.1 and $4.5 \mathrm{~min}$, maintaining at $50 \%$ from 4.5 to $8 \mathrm{~min}$, and then decreased to $17 \%$ over $1 \mathrm{~min}$, followed by column equilibration during $4 \mathrm{~min}$. The total run time was, thus, $13 \mathrm{~min}$ per sample. Data acquisition was performed in single reaction monitoring mode with a mass spectrometer (API 2000 triple quadrupole mass spectrometer from AB Sciex, MA, USA) equipped with an electrospray ionization interface (ESI) operating in the positive ion mode for all analytes except E-3174, whose data were acquired in negative mode from 8.5 to $13 \mathrm{~min}$. The mass transitions were as follows: $\mathrm{m} / \mathrm{z} 195.1 \rightarrow 138.2$ for $\mathrm{CAF}, \quad \mathrm{m} / \mathrm{z} \quad 181.2 \rightarrow 123.8$ for $1,7-\mathrm{X}, \quad \mathrm{m} / \mathrm{z}$ $346.1 \rightarrow 197.9$ for $\mathrm{OZ}, \mathrm{m} / \mathrm{z} 362.0 \rightarrow 214.1$ for $5-\mathrm{OZ}$, $\mathrm{m} / \mathrm{z} 423.0 \rightarrow 207.1$ for $\mathrm{LOS}, \mathrm{m} / \mathrm{z} 434.9 \rightarrow 157.0$ for E-3174, $\mathrm{m} / \mathrm{z} \quad 272.1 \rightarrow 171.1$ for $\mathrm{DM}, \quad \mathrm{m} / \mathrm{z}$ $258.1 \rightarrow 157.0$ for $\mathrm{DX}, \mathrm{m} / \mathrm{z} 258.1 \rightarrow 128.2$ for 3 $\mathrm{MM}$ and $\mathrm{m} / \mathrm{z} 284.2 \rightarrow 157.1$ for levallorphan (IS).

\section{Pharmacokinetic analysis}

The plasma concentration-time profiles of the probe drugs and their metabolites obtained from each rat were submitted to a non-compartmental pharmacokinetic analysis using the WinNonlin ${ }^{\circledR}$ version 5.2 (Pharsight Co, Mountain View, CA, USA). The maximum concentrations in plasma $\left(\mathrm{C}_{\max }\right)$ and the time to reach $\mathrm{C}_{\max }\left(\mathrm{t}_{\max }\right)$ were directly obtained from the experimental data. Other pharmacokinetic parameters estimated from the individual plasma concentration-time profiles were: the area under the concentration time-curve (AUC) from time zero to the time of the last quantifiable concentration $\left(\mathrm{AUC}_{0-\mathrm{t}}\right)$, calculated by the linear trapezoidal rule; $\mathrm{AUC}$ from time zero to infinite $\left(\mathrm{AUC}_{0-\infty}\right)$, calculated from $\mathrm{AUC}_{0-\mathrm{t}}+$ $\left(\mathrm{C}_{\text {last }} / \mathrm{k}_{\mathrm{el}}\right)$, where $\mathrm{C}_{\text {last }}$ is the last quantifiable concentration and $\mathrm{k}_{\mathrm{el}}$ is the apparent elimination rate constant estimated by log-linear regression of the terminal segment of the concentration-time profile; and the apparent terminal elimination halflife $\left(t_{1 / 2}\right)$. When the concentration of the analytes was found to be lower than the limit of quantification (LOQ) of the assay, zero value was assigned for the pharmacokinetic calculations.

Additionally, the metabolic ratios (MRs) were determined according to the corresponding $\mathrm{C}_{\max }$ and $\mathrm{AUC}_{0-\mathrm{t}}$ pharmacokinetic parameters [i.e., $\mathrm{C}_{\max }$ (probe) $/ \mathrm{C}_{\max }$ (metabolite) and $\left.\mathrm{AUC}_{\text {probe }} / \mathrm{AUC}_{\text {metabolite }}\right]$ for each probe drug and then compared between treatment conditions (probe alone and cocktail).

\section{STATISTICAL ANALYSIS}

Data were reported as the mean \pm standard deviation (percentage of coefficient of variation), except for $t_{\max }$, expressed as the median value and the associated range (minimum and maximum values).

The Mann-Whitney non-parametric two-tailed test was employed for the analysis of pharmacokinetic differences among the groups of rats that were administered just one probe drug 
individually and the group of those rats which received the cocktail of the probe drugs. This statistical approach was separately employed for each of the four-probe drugs included in the CEIBA cocktail, the corresponding metabolites and for the MRs calculated. Statistically significant differences were considered for $p$ values lower than $0.05(p<0.05)$.

\section{RESULTS}

The mean plasma concentration-time profiles of CAF, 1,7-X, OZ,5-OZ, LOS, E-3174, DM and DX after oral administration of the four probe drugs of the CEIBA cocktail alone or concurrently as a cocktail are shown in Figure 1. The respective main plasma pharmacokinetic parameters were determined and summarised in Table 1. Regarding the 3-MM, several values of concentrations below the LOQ were found in rat plasma, similarly to the phenomenon observed in humans $(4,25)$; thus, the 3-MM was properly quantified just in few samples and, therefore, it was not possible to carry out a suitable pharmacokinetic analysis for this compound (Table 1).

To infer about the potential application of the CEIBA cocktail in the assessment of multiple CYP-mediated drug interactions in Wistar rats, it was first analysed whether pharmacokinetic interactions occur between the probe drugs CAF, $\mathrm{OZ}, \mathrm{LOS}$ and $\mathrm{DM}$ when administered in combination as a cocktail. Overall, considering the mean plasma pharmacokinetic profiles depicted in Figure 1 for each probe drug and the corresponding metabolite when the probes were given individually and as part of the four-probe drug cocktail, it is observable the occurrence of pharmacokinetic-based drug interactions. The concomitant administration of the probe drugs as a cocktail resulted in the reduction of the systemic exposure (as assessed by $\mathrm{AUC}_{0-\mathrm{t}}$, Table 1), except for $\mathrm{OZ}$ and its metabolite (5-OZ). More specifically, the following mean decrease values of $\mathrm{AUC}_{0 \text {-t }}$ were detected: $56.1 \%$ for CAF, $58.0 \%$ for $1,7-\mathrm{X}, 68.8 \%$ for DM, $62.3 \%$ for DX, $21.5 \%$ for LOS and $61.1 \%$ for E-3174. On the contrary, an increase of mean $\mathrm{AUC}_{0-\mathrm{t}}$ value of $137.7 \%$ was observed for $\mathrm{OZ}$, while no significant difference in the systemic exposure for $5-\mathrm{OZ}$ was found when $\mathrm{OZ}$ was given alone and as a part of the cocktail. Nevertheless, statistically significant differences were found for CAF, 1,7-X, DX and E-3174 ( $p<$ $0.05)$. In agreement with the reduction of the extent of systemic exposure observed for CAF, 1,7-X, DX and E-3174, a statistically significant decrease of the peak systemic exposure (as assessed by $\mathrm{C}_{\max }$,
Table 1) was also observed for these compounds when the probe drugs were administered togetheras a cocktail.

Given the pharmacokinetic interactions documented when the four probe drugs (CAF, OZ, LOS and DM) were co-administered, a secondary analysis of the pharmacokinetic data was performed to evaluate whether metabolic interactions occurred. Thus, the influence of these pharmacokinetic-based drug interactions on the MRs was determined by comparison and statistical analysis of the calculated $\mathrm{C}_{\max (\text { probe) }} / \mathrm{C}_{\max }$ (metabolite) and $\mathrm{AUC}_{\text {probe }} / \mathrm{AUC}_{\text {metabolite }}$ ratios for each probe drug when administered alone and concurrently as a cocktail (Table 2). More specifically, a statistically significant increase for the LOS/E3174 probe drug-metabolite pair was found when LOS was administered as a part of the cocktail (Table 2). This result seems to be mainly associated with the significant decrease of the systemic exposure of E-3174 after the administration of LOS as part of the CEIBA cocktail (Table 1).

Moreover, no signal of acute toxicity was detected after the administration of each probe drug alone or together as CEIBA cocktail in any of the rats studied. Therefore, no important pharmacodynamic interactions between any of the probe drugs are anticipated when co-administrated to Wistar rats.

\section{DISCUSSION}

The global aim of this work was to assess the usefulness of the CEIBA cocktail in the nonclinical evaluation of metabolic-based drug interactions in Wistar rats, as it was originally designed and utilised to measure the specific-metabolic activity of CYP isoenzymes (CYP1A2, CYP2C9, CYP2C19, CYP2D6 and CYP3A4) in humans (41). Several important differences between human and rat CYP isoenzymes involved in the metabolism of the four probe drugs of the CEIBA cocktail were previously confirmed, as shown in Table 3 (26,42-46). In humans, each probe drug is mainly metabolized by a unique CYP isoenzyme, which is not significantly involved in the metabolism of the other probes, whereas this selectivity is not so strict in rats. More specifically, the probe drugs of the CEIBA cocktail share some CYP isoenzymes in the rat and, consequently, various isoenzymes can simultaneously be involved in the metabolism of different probe drugs of the cocktail, enhancing the risk of remarkable metabolic interactions (Table 3). 

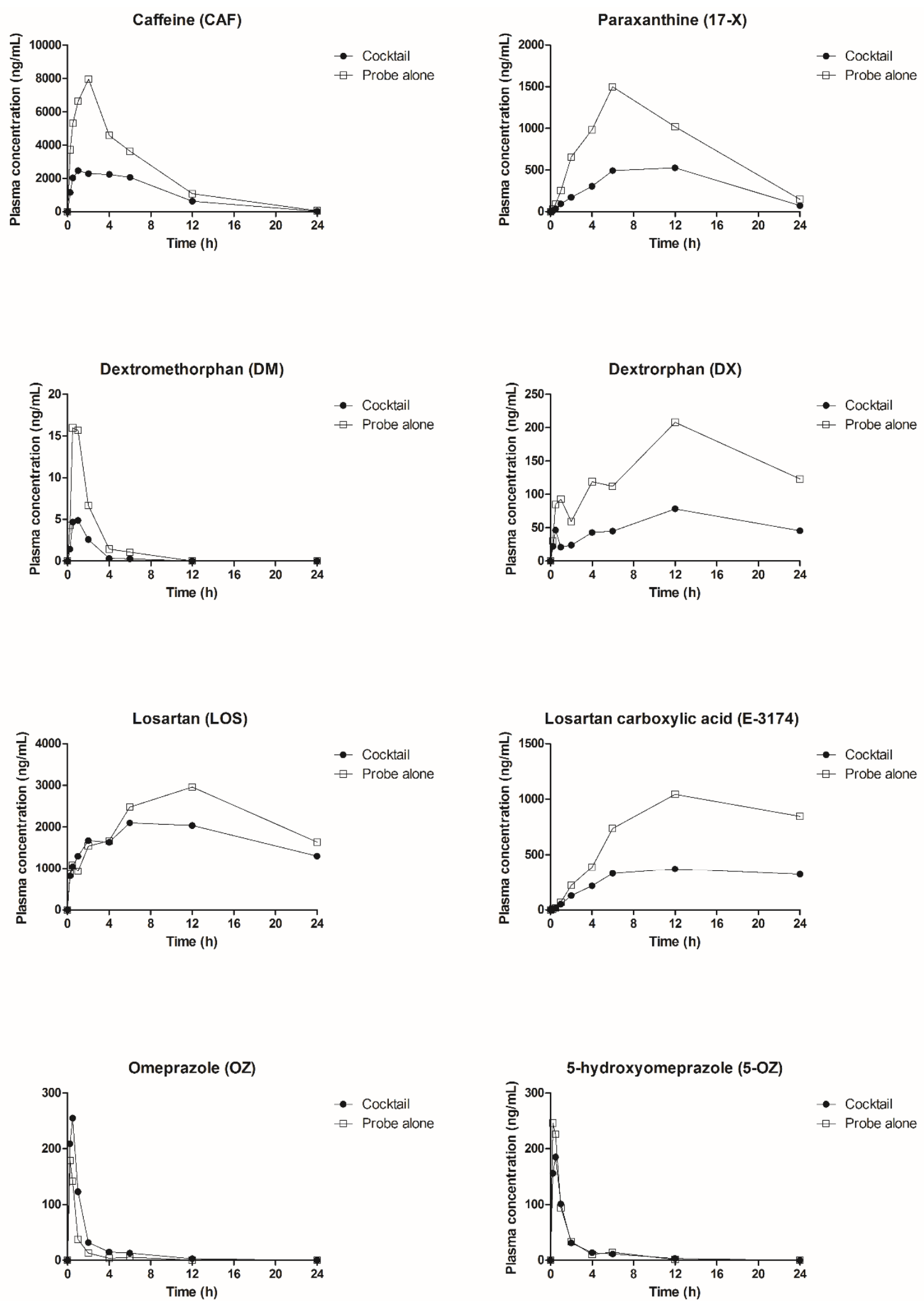

Figure 1. Mean plasma concentration-time profiles of each probe drug and the corresponding metabolites after the oral administration of the probe drugs alone or concomitantly as part of the CEIBA cocktail to Wistar rats. 
Table 1. Mean pharmacokinetic parameters estimated by non-compartmental analysis of the plasma concentration-time profiles of each probe administered alone and concomitantly as a cocktail [mean \pm standard deviation $\left(\mathrm{CV}, \%\right.$ ) except for $\mathrm{t}_{\max }$, where values are the median (min, max); $n=5$ unless otherwise noted].

\begin{tabular}{|c|c|c|c|c|c|c|}
\hline Probe drug & Treatment & $\mathrm{C}_{\max }(\mathrm{ng} / \mathrm{mL})$ & $t_{\max }(h)$ & $\operatorname{AUC}_{0-\mathrm{t}}(\mathbf{n g} \cdot \mathbf{h} / \mathbf{m L})$ & $\mathbf{A U C}_{0-\infty}(\mathbf{n g} \cdot \mathbf{h} / \mathbf{m L})$ & $\mathbf{t}_{1 / 2}(\mathbf{h})$ \\
\hline \multirow[t]{2}{*}{ CAF } & \multirow{2}{*}{$\begin{array}{l}\text { Probe alone } \\
\text { Cocktail }\end{array}$} & $8284 \pm 1897(22.9 \%)$ & $2.00(0.50,2.00)$ & $53310 \pm 13008(24.4 \%)$ & $53721 \pm 12881(24 \%)$ & $2.89 \pm 0.61(21.1 \%)$ \\
\hline & & $2621 \pm 440(16.8 \%) *$ & $1.00(0.50,6.00)$ & $23395 \pm 2342(10 \%) *$ & $25356 \pm 3795(15 \%) *$ & $3.83 \pm 1.42(37.1 \%)$ \\
\hline \multirow[t]{2}{*}{$1,7-\mathrm{X}$} & \multirow{2}{*}{$\begin{array}{l}\text { Probe alone } \\
\text { Cocktail }\end{array}$} & $1498 \pm 903(60.3 \%)$ & 6.00 & $19225 \pm 9749(50.7 \%)$ & $20400 \pm 10219(50.1 \%)$ & $5.25 \pm 1.17(22.2 \%)$ \\
\hline & & $546 \pm 203(37.2 \%) *$ & $6.00(6.00,12.00)$ & $8081 \pm 2863(35.4 \%) *$ & $7757 \pm 2896(37.3 \%) *$ & $7.59 \pm 3.06(40.3 \%)$ \\
\hline \multirow[t]{2}{*}{$\mathrm{DM}$} & \multirow{2}{*}{$\begin{array}{l}\text { Probe alone } \\
\text { Cocktail }\end{array}$} & $17.4 \pm 20.5(118 \%)$ & $0.50(0.25,1.00)$ & $32.3 \pm 34.4(106 \%)$ & $56.0 \pm 29.4^{\mathrm{d}}(52.4 \%)$ & $1.72 \pm 0.79^{\mathrm{d}}(45.9 \%)$ \\
\hline & & $5.84 \pm 3.78^{\mathrm{c}}(64.7 \%)$ & $0.50^{\mathrm{c}}$ & $10.1 \pm 7.28^{\mathrm{c}}(72 \%)$ & $15.2 \pm 9.9^{\mathrm{c}}(64.8 \%)$ & $1.63 \pm 0.55^{\mathrm{c}}(33.7 \%)$ \\
\hline \multirow[t]{2}{*}{ DX } & \multirow{2}{*}{$\begin{array}{l}\text { Probe alone } \\
\text { Cocktail }\end{array}$} & $215 \pm 103(48 \%)$ & $12.00(0.50,12.00)$ & $3489 \pm 1490(42.7 \%)$ & ND & $33.9^{\mathrm{a}}$ \\
\hline & & $85.7 \pm 33.3(38.9 \%) *$ & $12.00(0.50,12.00)$ & $1314 \pm 529(40.2 \%) *$ & ND & ND \\
\hline \multirow[t]{2}{*}{ 3-MM } & \multirow{2}{*}{$\begin{array}{l}\text { Probe alone } \\
\text { Cocktail }\end{array}$} & $34.2 \pm 47.7(139 \%)$ & $0.50(0.25,6.00)$ & $94.2^{\mathrm{b}}$ & ND & $1.33^{\mathrm{a}}$ \\
\hline & & $1.87^{\mathrm{b}}$ & $2.50(1.00,4.00)^{b}$ & ND & ND & ND \\
\hline \multirow[t]{2}{*}{ LOS } & \multirow{2}{*}{$\begin{array}{l}\text { Probe alone } \\
\text { Cocktail }\end{array}$} & $3261 \pm 1169(35.8 \%)$ & $6.00(2.00,12.00)$ & $53321 \pm 22437(42.1 \%)$ & $50981 \pm 22326^{\mathrm{c}}(43.8 \%)$ & $8.74 \pm 1.07^{\mathrm{c}}(12.2 \%)$ \\
\hline & & $2488 \pm 847(34 \%)$ & $6.00(6.00,24.00)$ & $41847 \pm 16852(40.3 \%)$ & $68588 \pm 55872^{c}(81.5 \%)$ & $13.1 \pm 10.3^{\mathrm{c}}(78.3 \%)$ \\
\hline \multirow[t]{2}{*}{ E-3174 } & \multirow{2}{*}{$\begin{array}{l}\text { Probe alone } \\
\text { Cocktail }\end{array}$} & $1145 \pm 379(33.1 \%)$ & $12.00(6.00,24.00)$ & $18578 \pm 5505(29.6 \%)$ & $18027^{\mathrm{a}}$ & $15.0^{\mathrm{a}}$ \\
\hline & & $458 \pm 200(43.7 \%) *$ & $12.00(6.00,24.00)$ & $7233 \pm 2763(38.2 \%) *$ & $18259^{\mathrm{b}}$ & $26.9^{\mathrm{b}}$ \\
\hline \multirow[t]{2}{*}{$\mathrm{OZ}$} & \multirow{2}{*}{$\begin{array}{l}\text { Probe alone } \\
\text { Cocktail }\end{array}$} & $179 \pm 116(65.1 \%)$ & 0.25 & $162 \pm 101(62.1 \%)$ & $189 \pm 102^{\mathrm{d}}(54 \%)$ & $2.11 \pm 2.01^{\mathrm{d}}(95.2 \%)$ \\
\hline & & $267 \pm 133(50 \%)$ & $0.5(0.25,0.50)$ & $385 \pm 207(53.8 \%)$ & $400 \pm 203(50.6 \%)$ & $3.44 \pm 1.78(51.9 \%)$ \\
\hline \multirow[t]{2}{*}{$5-\mathrm{OZ}$} & Probe alone & $254 \pm 203(79.7 \%)$ & $0.25(0.25,0.50)$ & $317 \pm 203(64 \%)$ & $297 \pm 115^{\mathrm{d}}(38.6 \%)$ & $2.95 \pm 2.40^{\mathrm{d}}(81.55 \%)$ \\
\hline & Cocktail & $199 \pm 64.9(32.6)$ & $0.50(0.25,0.50)$ & $318 \pm 127(39.9 \%)$ & $329 \pm 125(37.9 \%)$ & $2.98 \pm 1.01(33.9 \%)$ \\
\hline
\end{tabular}


Table 2. Metabolic ratios [mean \pm standard deviation $(\mathrm{CV} \%)$ ] calculated for each probe drug-metabolite pair according to the main pharmacokinetic parameters $\left(\mathrm{C}_{\max }\right.$ and $\left.\mathrm{AUC}_{0-\mathrm{t}}\right)$ estimated when each probe was administered alone and concurrently as a cocktail. $n=5$ unless otherwise noted.

\begin{tabular}{|c|c|c|c|}
\hline Probe drug/ metabolite & Treatment & $\mathrm{C}_{\max } \mathrm{MR}$ & $\mathbf{A U C} \mathbf{C}_{0-\mathrm{t}} \mathbf{M R}$ \\
\hline CAF/1,7-X & $\begin{array}{l}\text { Probe alone } \\
\text { Cocktail }\end{array}$ & $\begin{array}{l}6.49 \pm 2.517(38.8 \%) \\
5.24 \pm 1.569(30.0 \%)\end{array}$ & $\begin{array}{l}3.00 \pm 0.638(21.3 \%) \\
3.27 \pm 1.383(42.3 \%)\end{array}$ \\
\hline DM/DX & $\begin{array}{l}\text { Probe alone } \\
\text { Cocktail }\end{array}$ & $\begin{array}{l}0.11 \pm 0.173(157 \%) \\
0.06 \pm 0.035(59.5 \%)^{\mathrm{a}}\end{array}$ & $\begin{array}{l}0.01 \pm 0.016(143 \%) \\
0.01 \pm 0.004(61.4 \%)^{\mathrm{a}}\end{array}$ \\
\hline LOS/E-3174 & $\begin{array}{l}\text { Probe alone } \\
\text { Cocktail }\end{array}$ & $\begin{array}{l}2.87 \pm 0.462(16.1 \%) \\
5.64 \pm 1.074(19.0 \%)^{*}\end{array}$ & $\begin{array}{l}2.85 \pm 0.923(32.4 \%) \\
5.78 \pm 0.744(12.9 \%)^{*}\end{array}$ \\
\hline OZ/5-OZ & $\begin{array}{l}\text { Probe alone } \\
\text { Cocktail }\end{array}$ & $\begin{array}{l}0.76 \pm 0.096(12.7 \%) \\
1.27 \pm 0.361(28.4 \%)\end{array}$ & $\begin{array}{l}0.78 \pm 0.774(99.5 \%) \\
1.16 \pm 0.299(25.8 \%)\end{array}$ \\
\hline \multicolumn{4}{|c|}{$\begin{array}{l}\text { CAF, caffeine; 1,7-X, 1,7-dimethylxanthine (paraxanthine); DM, dextromethorphan; DX, dextrorphan; 3-MM, 3- } \\
\text { methoxymorphinan; LOS, losartan; E-3174, losartan carboxylic acid; OZ, omeprazole; 5-OZ, 5-hydroxyomeprazole; } \\
\mathrm{C}_{\max } \text {, maximum concentration in plasma; AUC } \mathrm{C}_{0-\mathrm{t}} \text {, area under the drug concentration time-curve from time zero to the } \\
\text { time of the last quantifiable concentration. }{ }^{*} p<0.05 \text {, significantly different from the group in which the probe was } \\
\text { administered alone; }{ }^{\mathrm{a}} n=4 \text {. }\end{array}$} \\
\hline
\end{tabular}

This suggests that potential enzyme competition or saturation phenomena in some of the metabolic pathways may occur in the rat. Hence, these findings raise the need to demonstrate the utility and validity of the CEIBA cocktail in Wistar rats. To the best of our knowledge, no drug-drug interactions involving the probe drugs of the CEIBA cocktail were described in rats. Thus, the present study shows, for the first time, that pharmacokinetic-based drug interactions affecting the CAF, 1,7-X, DX and E-3174 may occur in Wistar rats when the four probe drugs are administered as a cocktail at the selected doses. Regarding the nature of these pharmacokinetic interactions, the differences found in CAF and 1,7$\mathrm{X}$ (probe alone versus cocktail) are probably related with drug interactions occurring at the level of gastrointestinal tract affecting the extent of absorption of CAF and, consequently, the extent of its metabolism to $1,7-\mathrm{X}$; on the contrary, the discrepancy in the results obtained for DX and E3174 (probe alone versus cocktail) seems to be associated with metabolic drug interactions.

For CAF and 1,7-X, a similar decrease in the mean total systemic exposure was observed for both compounds ( $56.1 \%$ and $58.0 \%$, respectively) after the administration of the CEIBA cocktail. Considering that 1,7-X directly depends on the rate and extent of the biotransformation of CAF, the variability observed in this study could be explained by either a global decrease of the absorption of CAF or an increase of the elimination of the drug and metabolite. However, if the reduction in the systemic exposure was mainly due to an increased efficiency of the elimination process, it would be expected a significant decrease in the $t_{1 / 2}$ values and, in contrast, an average increase occurred, although not statistically significant. Therefore, a lower absorption of CAF is likely the main process responsible for the results achieved, having a roughly proportional impact in the values of $\mathrm{AUC}_{0}$ t, $\mathrm{AUC}_{0-\infty}$ and $\mathrm{C}_{\max }$ of CAF and, subsequently, of its metabolite 1,7-X (Table 1).

For DX (DM metabolite) and E-3174 (LOS metabolite) a significant decrease in the systemic exposure was also observed when the rats received the probe drugs as a cocktail but, at this point it is noteworthy that no relevant differences were found in the pharmacokinetic profiles of the parent drugs (DM and LOS) (Table 1). Thus, the hypothesis of absorption-related drug interactions is not plausible.

In rat, LOS is mostly metabolized to E-3174 by CYP2C11, an isoenzyme secondarily involved in the biotransformation of CAF to 1,7-X. Thus, the concomitant administration of CAF and LOS can saturate the CYP2C11 metabolic capacity, leading that LOS was predominantly metabolized by a route other than LOS-E-3174. This may explain the decrease of the systemic exposure of E-3174 observed, without significant pharmacokinetic differences for the parent drug (LOS). In addition, the pharmacokinetic profiles of CAF and 1,7-X did not reflect any metabolic interaction, probably because the metabolism of CAF to $1,7-\mathrm{X}$ is mainly mediated by CYP1A2 in rats, an isoenzyme that is unlikely to be subject to a high level of competition and/or saturation phenomena (Table 3 ). 
Table 3. Comparison of the human and rat drug-metabolizing CYP isoenzymes for the probe drugs included in the CEIBA cocktail $(26,42-46)$.

\begin{tabular}{lll}
\hline Human isoenzyme & Rat isoenzyme & Probe drug/metabolite \\
\hline CYP1A2 & CYP1A2; CYP2C11 & CAF/1,7-X \\
CYP2C9 & CYP2C11 & LOS/E-3174 \\
CYP2C19 & CYP2D1/2; CYP1A1/2; CYP3A1/2 & OZ/5-OZ \\
CYP2D6 & CYP2D2 & DM/DX \\
CYP3A4 & CYP3A1/2 & DM/3-MM \\
\hline $\begin{array}{l}\text { CYP isoenzymes in italics represent secondary metabolism pathways. CAF, caffeine; 1,7-X, 1,7-dimethylxanthine; } \\
\text { DM, dextromethorphan; DX, dextrorphan; 3-MM, 3-methoxymorphinan; LOS, losartan; E-3174, losartan carboxylic } \\
\text { acid; OZ, omeprazole; 5-OZ, 5-hydroxyomeprazole; }\end{array}$ \\
\hline
\end{tabular}

On the other hand, CYP2D2 is the main isoenzyme responsible for the metabolic conversion of DM to DX, although it is also involved in the biotransformation of $\mathrm{OZ}$ to $5-\mathrm{OZ}$. Therefore, the same hypothesis of metabolic competition/saturation may be eligible to explain the significant pharmacokinetic differences found for DX (probe alone versus cocktail), but not for $\mathrm{DM}, \mathrm{OZ}$ and 5-OZ. Similarly, OZ can be metabolized to $5-\mathrm{OZ}$ by other isoenzymes such as CYP1A2 and CYP3A1/2, and DM can be metabolized to other compounds in addition to DX, such as 3-MM (Table 3).

Given that some pharmacokinetic-based drug interactions were detected in Wistar rats, its potential influence on the MRs has been additionally analysed to investigate the usefulness of the CEIBA cocktail in the assessment of CYPmediated metabolism. For this study, $\mathrm{AUC}_{0-\mathrm{t}}$ and $\mathrm{C}_{\max }$ were assumed as the main pharmacokinetic parameters that better reflect the drug/metabolite ratio profile for each probe drug and, therefore, they were considered as the best end-points to evaluate the magnitude of such probe drug interactions on the phenotypic metric.

On this matter, the results demonstrate that despite the occurrence of drug-drug interactions at the doses tested, it is not expected that MRs are substantially modified in rats, as the drug/metabolite ratio profiles assessed by $\mathrm{AUC}_{0-\mathrm{t}}$ and $\mathrm{C}_{\max }$ ratios are similar when the probe drugs were administered alone or concomitantly as a cocktail, except for LOS/E-3174 $(p<0.05$, Table 2). Overall, this means that the CEIBA cocktail can be utilised to study metabolic-based-drug interactions in Wistar rats involving CYP1A2, CYP2D1/2 and CYP2D2, using the CAF/1,7-X, $\mathrm{OZ} / 5-\mathrm{OZ}$ and $\mathrm{DM} / \mathrm{DX}$ ratios, respectively.

This study also confirms the interspecies differences between rat and human CYP isoenzymes and highlights the need of interspecies comparisons at pharmacokinetics and on the metabolism of the probe drugs when used as a cocktail. Lastly, it is also important to remark that the current work should be viewed as part of the rational process of extrapolation and optimization of the CEIBA cocktail to rat.

\section{CONCLUSION}

The CEIBA cocktail designed for humans may be used to evaluate metabolic-based drug interactions in the rat involving the CYP1A2, CYP2D1/2 and CYP2D2, by means of the CAF/1,7-X, OZ/5-OZ and $\mathrm{DM} / \mathrm{DX}$ ratios, respectively.

Since very few CYP phenotyping cocktail approaches are described to the rat, the present study is of great value as it demonstrates the validity of the CEIBA cocktail to study in vivo drug interactions in this species. However, to extend the applicability of the CEIBA cocktail to a greater number of CYP isoenzymes some optimization is required, particularly the selection of more appropriate probe drugs for CYP3A1/2 and CYP2C11 isoenzymes.

\section{ACKNOWLEDGMENTS}

The authors are grateful to Fundação para a Ciência e a Tecnologia (Lisbon, Portugal) for the $\mathrm{PhD}$ fellowship of Paulo Magalhães (SFRH/BD/85069/2012), involving the POPHQREN, which is co-funded by FSE and MEC. The authors also acknowledge the support provided by FEDER funds through the POCI - COMPETE 2020 - Operational Programme Competitiveness and Internationalisation in Axis I - Strengthening research, technological development and innovation (Project No. 007491) and National Funds by FCT - Foundation for Science and 
Technology (Project UID/Multi /00709). This study was also partially supported (FdA) by Instituto de Salud Carlos III-Sara Borrell program (CD13/00348, Spain).

\section{REFERENCES}

1. Samer CF, Lorenzini KI, Rollason V, Daali Y, Desmeules JA. Applications of CYP450 testing in the clinical setting. Mol Diagn Ther. 2013; 17:16584.

2. Uchida S, Tanaka S, Namiki N. Simultaneous and comprehensive in vivo analysis of cytochrome P450 activity by using a cocktail approach in rats. Biopharm Drug Dispos. 2014; 35:228-36.

3. de Andrés F, Sosa-Macías M, Lazalde-Ramos BP, Naranjo MEG, Tarazona-Santos E, Llerena A. Evaluation of drug-metabolizing enzyme hydroxylation phenotypes in Hispanic populations: the CEIBA cocktail. Drug Metabol Drug Interact. 2013;28:135-46.

4. de Andrés F, Sosa-Macías M, Llerena A. A rapid and simple LC-MS/MS method for the simultaneous evaluation of CYP1A2, CYP2C9, CYP2C19, CYP2D6 and CYP3A4 hydroxylation capacity. Bioanalysis. 2014; 6:683-96.

5. Magalhães $P$, Alves G, Llerena A, Falcão A. Venlafaxine pharmacokinetics focused on drug metabolism and potential biomarkers. Drug Metabol Drug Interact. 2014; 29:129-41.

6. Vital-lopez FG, Wallqvist A, Reifman J. Bridging the gap between gene expression and metabolic phenotype via kinetic models. BMC Syst Biol. 2013; 7:63.

7. Crisafulli C, Fabbri C, Porcelli S, Drago A, Spina E, De Ronchi D, et al. Pharmacogenetics of antidepressants. Front Pharmacol. 2011; 2:6.

8. Llerena A, Dorado P, Ramírez R, González I, Alvarez M, Peñas-Lledó EM, et al. CYP2D6 genotype and debrisoquine hydroxylation phenotype in Cubans and Nicaraguans. Pharmacogenomics J. 2012; 12:176-83.

9. Llerena A, Dorado P, Peñas-Lledó EM. Pharmacogenetics of debrisoquine and its use as a marker for CYP2D6 hydroxylation capacity. Pharmacogenomics. 2009; 10:17-28.

10. Zhu B. Assessment of cytochrome P450 activity by a five-drug cocktail approach. Clin Pharmacol Ther. 2001; 70:455-61.

11. Wohlfarth A, Naue J, Lutz-Bonengel S, Dresen S, Auwärter V. Cocktail approach for in vivo phenotyping of 5 major CYP450 isoenzymes: development of an effective sampling, extraction, and analytical procedure and pilot study with comparative genotyping. J Clin Pharmacol. 2012; 52:1200-14.

12. Tanaka S, Uchida S, Inui N, Takeuchi K, Watanabe H, Namiki N. Simultaneous LC-MS/MS analysis of the plasma concentrations of a cocktail of 5 cytochrome P450 substrate drugs and their metabolites. Biol Pharm Bull. 2014; 37:18-25.

13. Frye RF, Matzke GR, Adedoyin A, Porter JA,
Branch RA. Validation of the five-drug 'Pittsburgh cocktail' approach for assessment of selective regulation of drug-metabolizing enzymes. Clin Pharmacol Ther. 1997; 62:365-76.

14. Zgheib NK, Frye RF, Tracy TS, Romkes M, Branch RA. Validation of incorporating flurbiprofen into the Pittsburgh cocktail. Clin Pharmacol Ther. 2006; 80:257-63.

15. Scott RJ, Palmer J, Lewis IA, Pleasance S. Determination of a 'GW cocktail' of cytochrome P450 probe substrates and their metabolites in plasma and urine using automated solid phase extraction and fast gradient liquid chromatography tandem mass spectrometry. Rapid Commun Mass Spectrom. 1999; 13:2305-19.

16. Streetman DS, Bleakley JF, Kim JS, Nafziger AN, Leeder JS, Gaedigk A, et al. Combined phenotypic assessment of CYP1A2, CYP2C19, CYP2D6, CYP3A, N-acetyltransferase-2, and xanthine oxidase with the 'Cooperstown cocktail'. Clin Pharmacol Ther. 2000; 68:375-83.

17. Tanaka E, Kurata N, Yasuhara H. How useful is the 'cocktail approach' for evaluating human hepatic drug metabolizing capacity using cytochrome P450 phenotyping probes in vivo? J Clin Pharm Ther. 2003; 28:157-65.

18. Chainuvati S, Nafziger AN, Leeder JS, Gaedigk A, Kearns GL, Sellers E, et al. Combined phenotypic assessment of cytochrome p450 1A2, 2C9, 2C19, 2D6, and 3A, N-acetyltransferase-2, and xanthine oxidase activities with the 'Cooperstown 5+1 cocktail'. Clin Pharmacol Ther. 2003; 74:437-47.

19. Christensen M, Andersson K, Dalén P, Mirghani RA, Muirhead GJ, Nordmark A, et al. The Karolinska cocktail for phenotyping of five human cytochrome P450 enzymes. Clin Pharmacol Ther. 2003; 73:517-28.

20. Turpault S, Brian W, Van Horn R, Santoni A, Poitiers F, Donazzolo Y, et al. Pharmacokinetic assessment of a five-probe cocktail for CYPs 1A2, 2C9, 2C19, 2D6 and 3A. Br J Clin Pharmacol. 2009; 68:928-35.

21. Ryu JY, Song IS, Sunwoo YE, Shon JH, Liu KH, Cha IJ, et al. Development of the 'Inje cocktail' for high-throughput evaluation of five human cytochrome P450 isoforms in vivo. Clin Pharmacol Ther. 2007; 82:531-40.

22. Videau O, Delaforge M, Levi M, Thévenot E, Gal $\mathrm{O}$, Becquemont L, et al. Biochemical and analytical development of the CIME cocktail for drug fate assessment in humans. Rapid Commun Mass Spectrom. 2010; 24:2407-19.

23. Donzelli M, Derungs A, Serratore M-G, Noppen C, Nezic L, Krähenbühl S, et al. The basel cocktail for simultaneous phenotyping of human cytochrome P450 isoforms in plasma, saliva and dried blood spots. Clin Pharmacokinet. 2014; 53:271-82.

24. Bosilkovska M, Samer CF, Déglon J, Rebsamen M, Staub C, Dayer P, et al. Geneva cocktail for cytochrome p450 and P-glycoprotein activity assessment using dried blood spots. Clin Pharmacol Ther. 2014; 96:349-59. 
25. de Andrés F, Terán S, Bovera M, Fariñas H, Terán E, LLerena A. Multiplex Phenotyping for Systems Medicine: A One-Point Optimized Practical Sampling Strategy for Simultaneous Estimation of CYP1A2, CYP2C9, CYP2C19, and CYP2D6 Activities Using a Cocktail Approach. OMICS. 2016; 20:88-96.

26. Videau O, Pitarque S, Troncale S, Hery $\mathrm{P}$, Thévenot E, Delaforge $M$, et al. Can a cocktail designed for phenotyping pharmacokinetics and metabolism enzymes in human be used efficiently in rat? Xenobiotica. 2012; 42:349-54.

27. Geng T, Si H, Kang D, Li Y, Huang W, Ding G, et al. Influences of Re Du Ning Injection, a traditional Chinese medicine injection, on the CYP450 activities in rats using a cocktail method. J Ethnopharmacol. 2015; 174:426-36.

28. Li X, Li Y, Gong W, Yang MY, Yang Y, Li ZP, et al. Auto-Induction Effect of Chloroxoquinoline on the Cytochrome P450 Enzymes of Rats Associated with CYP 3A and 1A. PLoS One. 2015; 10:e0138875.

29. Xia C, Sun J, Wang G, Shang L, Zhang X, Zhang $R$, et al. Herb-drug interactions: in vivo and in vitro effect of Shenmai injection, a herbal preparation, on the metabolic activities of hepatic cytochrome $\mathrm{P} 450$ $3 \mathrm{~A} 1 / 2,2 \mathrm{C} 6,1 \mathrm{~A} 2$, and 2E1 in rats. Planta Med. 2010; 76:245-50.

30. Zhu S, Gao J, Shi Z, QLi G, Chen Z, Yao M. Inhibitory effect of Aristolochia fruit on Cytochrome P450 isozymes in vitro and in vivo. Pak J Pharm Sci. 2015; 28:939-44.

31. Zhang S, Song N, Li Q, Fan H, Liu C. Liquid chromatography/tandem mass spectrometry method for simultaneous evaluation of activities of five cytochrome P450s using a five-drug cocktail and application to cytochrome P450 phenotyping studies in rats. J Chromatogr B. 2008; 871(1):7889.

32. Guo Y-J, Zheng S-L. Effect of myricetin on cytochrome P450 isoforms CYP1A2, CYP2C9 and CYP3A4 in rats. Pharmazie. 2014; 69:306-10.

33. Zhu H-D, Gu N, Wang M, Kong H-R, Zhou M-T. Effects of capsicine on rat cytochrome P450 isoforms CYP1A2, CYP2C19, and CYP3A4. Drug Dev Ind Pharm. 2015; 41:1824-8.

34. Cai J, Ma J, Xu K, Gao G, Xiang Y, Lin C. Effect of Radix Sophorae Tonkinensis on the activity of cytochrome P450 isoforms in rats. Int J Clin Exp Med. 2015; 8:9737-43.

35. Du X, Ye H, Zhang C, Ye L, Lin G. Effect of kanglaite on rat cytochrome P450. Pharm Biol. 2015; 53:995-1001.

36. Jin Y, Shao L, Li G, Shao M, Zhi Y, Zhu W. Assessment of effect of Zhu-tan Tong-luo decoction on CYP450 isoforms activity of rats. Int J Clin Exp Med. 2015; 8:15940-8.

37. Zhou C, Qiao L, Zhao L, Li Z. Evaluation of the impact of cantharidin on rat CYP enzymes by using a cocktail of probe drugs. Fitoterapia. 2015; 107:49-53.

38. Zhou Y, Wang S, Ding T, Chen M, Wang L, Wu
$M$, et al. Evaluation of the effect of apatinib (YN968D1) on cytochrome P450 enzymes with cocktail probe drugs in rats by UPLC-MS/MS. J Chromatogr B. 2014; 973:68-75.

39. Martignoni M, Groothuis GMM, de Kanter R. Species differences between mouse, rat, dog, monkey and human CYP-mediated drug metabolism, inhibition and induction. Expert Opin Drug Metab Toxicol. 2006; 2:875-94.

40. Jurica J, Kyr M, McCaskey Hadasova E, Tomandl J. Evaluation of the activity of P450 enzymes in rats: use of the single marker or combined drug administration. Neuro Endocrinol Lett. 2009; 30 Suppl 1:92-5.

41. de Andrés F, Terán S, Hernández F, Terán E and Llerena A. To Genotype or Phenotype for Personalized Medicine? CYP450 Drug Metabolizing Enzyme Genotype-Phenotype Concordance and Discordance in the Ecuadorian Population. Omi A J Integr Biol. 2016 (in press).

42. Kot M, Daniel WA. Caffeine as a marker substrate for testing cytochrome P450 activity in human and rat. Pharmacol Rep. 60:789-97.

43. Lee DY, Shin HS, Bae SK, Lee MG. Effects of enzyme inducers and inhibitors on the pharmacokinetics of intravenous omeprazole in rats. Biopharm Drug Dispos. 2006; 27:209-18.

44. Kobayashi K, Urashima K, Shimada N, Chiba K. Substrate specificity for rat cytochrome P450 (CYP) isoforms: screening with cDNA-expressed systems of the rat. Biochem Pharmacol. 2002; 63:889-96.

45. Kashfi K, McDougall CJ, Dannenberg AJ. Comparative effects of omeprazole on xenobiotic metabolizing enzymes in the rat and human. Clin Pharmacol Ther. 1995; 58:625-30.

46. Grobe N, Kutchan TM, Zenk MH. Rat CYP2D2, not 2D1, is functionally conserved with human CYP2D6 in endogenous morphine formation. FEBS Lett. 2012; 586:1749-53. 